Komplett-Service-Netzwerk

RalfIhl, Krefeld

\section{Fortbildung Neurologie}

36 CME: Neuropalliative Care

Palliativmedizin bei Patienten mit Parkinson-Erkrankungen

Christiane Weck und Stefan Lorenzl, Hausham, Salzburg

\section{Praxis konkret}

\section{Honorare: Psychotherapeutisches Erstgespräch und Akutbehandlung nachgebessert}

51 Rettungsdienst: Gericht bestätigt Selbstständigkeit der Honorarärzte

51 Zuerst der genaue Blick in die Bücher, dann die Praxisübernahme

52 Substitutionstherapie: Zwei neue extrabudgetäre Leistungen zum 1. Oktober

53 Ärzte wollen bei Digital Healthcare Taktgeber werden Umfrageergebnisse zur Digitalisierung in der Versorgung

54 Start-up setzt auf flexible Videosprechstunde

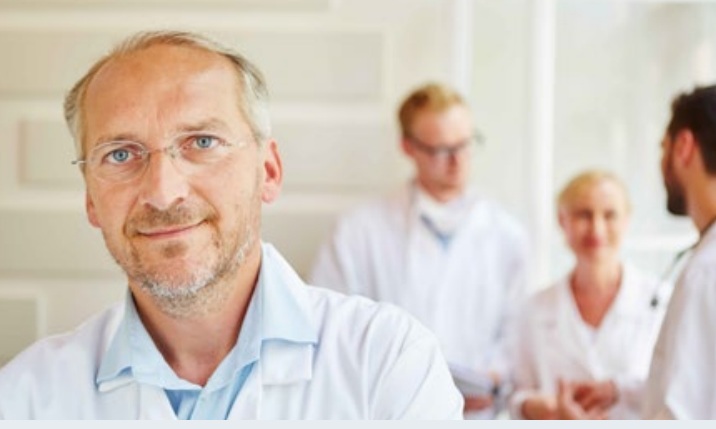

\section{Gerontopsychiatrie}

Bei älteren Patienten werden psychiatrische Störungen häufig durch somatische Erkrankungen und steigende Verlusterlebnisse erschwert. Spezialisierte Versorgungsstrukturen können die Teilhabe, Selbstständigkeit und -bestimmung sowie die Achtung der Menschenwürde sichern.

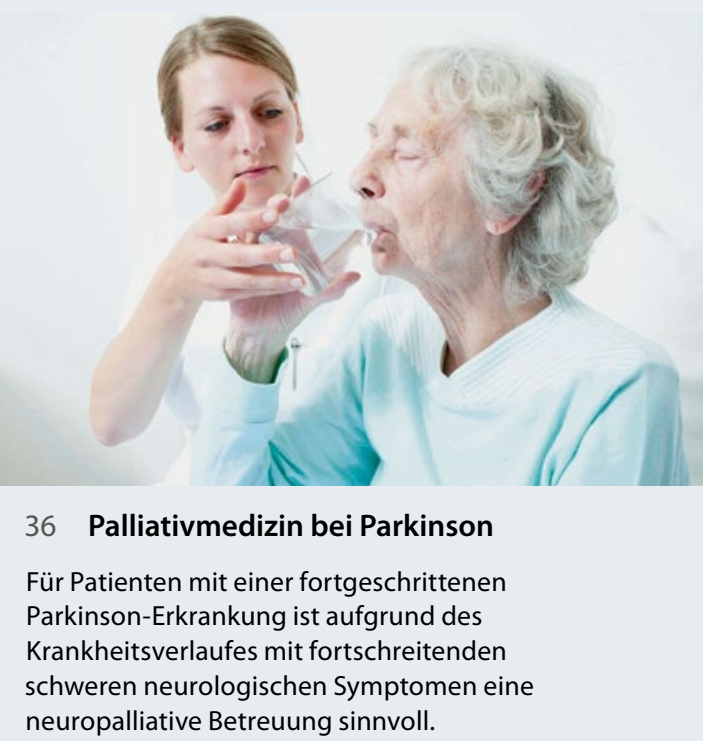

Belastende Symptomkonstellation: Neuropathischer Schmerz, Angst und Schlafstörungen

\section{Pharmawissen aktuell}

Schubförmig remittierende MS: Galtirameracetat auch als Generikum

\section{Unsere Autoren der CME-Fortbildung}

Legt die Versorgung gerontopsychiatrischer Patienten in einem KomplettService-Netzwerk dar. > Seite 30:

Prof. Dr. med. Ralf Ihl, Chefarzt der Klinik für Gerontopsychiatrie und -psychotherapie am Maria-Hilf-Krankenhaus, Alexianer in Krefeld

Erläutern die Besonderheiten und das zielgerichtete Vorgehen der Palliativmedizin bei Patienten mit Parkinson-Erkrankungen. > Seite 36: Univ.-Prof. Dr. med. Stefan Lorenzl, Dipl. Pall. Med. (Univ. Cardiff), Chefarzt, und Dr. med. univ. Christiane Weck, Funktionsoberärztin F\&E der Abteilung Neurologie und Neuropalliative Care des Krankenhauses Agatharied in Hausham

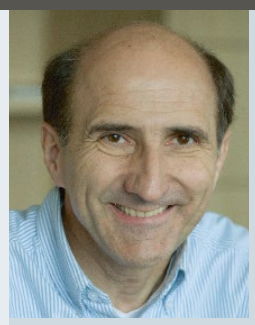

Prof. Dr. med. Ralf Ihl

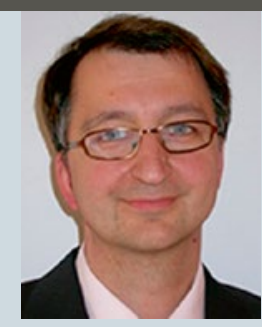

Univ.-Prof. Dr. med. Stefan Lorenzl, Dipl. Pall. Med. (Univ. Cardiff) 